\title{
EnTREVISTA: Dr. Paulo Manuel Pêgo Fernandes
}

\section{RM: Como funcionava o Departamento Científico na época em que o senhor era diretor? Quais são as diferenças para hoje em dia?}

O Departamento Científico tinha algumas atividades para os alunos na época, tinham duas ligas, uma era a liga da sífilis e outra a liga de combate à febre reumática. A liga da sífilis deve ter quase cem anos! Outra atividade era a farmácia do CAOC, que não é mais ativa hoje, funcionava da seguinte maneira, os laboratórios davam muitas amostras grátis e os alunos que as recebiam doavam para o CAOC. A farmácia funcionava no horário extracurricular, e nós alunos líamos as bulas, estudávamos o DEF (Dicionário de Especialidades Farmacêuticas), e distribuíamos os remédios para funcionários e outras pessoas que precisavam, inclusive outros alunos. Havia também a Revista de Medicina. Quando eu entrei na Faculdade em 1977, a revista não estava sendo editada, ou editavam uma por ano. Em 1980 decidimos retomar as atividades da revista, nessa ocasião eu fui convidado a ser um dos diretores da Revista. Em 1982, quando ocorreu o $1^{\circ}$ COMU ela serviu para publicar os resumos dos trabalhos apresentados e a íntegra dos projetos premiados. $\mathrm{Na}$ época eram 4 prêmios " $1^{\circ}$ lugar em área Clínica ou Cirúrgica, $1^{\circ}$ lugar em área Básica, $2^{\circ}$ e $3^{\circ}$ lugar." O Prêmio Oswaldo Cruz também tinha deixado de ser realizado,. Nós revivemos o prêmio em 1981, e em 1982 ele foi incorporado ao COMU para fortalecer as iniciativas. Em relação ao funcionamento no dia-a dia era uma coisa bem amadora, nos não tínhamos dinheiro, e tinha uma secretária que trabalhava meio período, e em algumas épocas não havia secretária, e os alunos tocavam tudo.

RM: O COMU Foi uma iniciativa em conjunto pelo pessoal do DC ou teve uma pessoa específica que o sugeriu?

O $1^{\circ}$ congresso médico que eu participei foi em 1978 e nós ganhamos prêmios nesse congresso, eu participava atividades 
que não eram ligas, mas era parecido. Para quem queria cirurgia especificamente havia várias atividades paralelas, como treinos de técnica cirúrgica e trabalhos científicos, até porque, naquela ocasião, para entrar na residência, isso contava mais até que a prova. Hoje em dia, por iniciativa do MEC (Ministério da Educação e Cultura), no sentido de deixar as provas mais uniformes e as pessoas terem uma chance mais equivalente, independente da faculdade que venham, privilegia-se a parte escrita. Isso faz o aluno perder o estímulo de fazer parte de atividades como iniciação cientifica. Na época diziam que você entrava na residência já sabendo operar. Já sabia a parte básica, pois já vinha treinado em animais e cadáveres. O currículo valia muito, incluindo trabalhos apresentados em congressos, publicações científicas, prêmios. Em 1978 eu fui apresentar um trabalha no COMU de Taubaté, fiquei em terceiro lugar. E isso traz um feedback positivo, estimulando a continuar a produção científica. A partir de então, começamos a participar de congressos em vários lugares, porém aqui na faculdade, aonde desde aquela época se tinha maior atividade cientifica, não havia nenhum congresso. A partir de 1980 comecei a ter a idéia de retomar a Revista de Medicina e o POC. E já veio a idéia formar o congresso em 1982. O congresso começou a ser pensado em 1980, mas até sair demorou 2 anos, pois não tinha nada, não tinha patrocínio, nem reconhecimento da faculdade. Quando fomos conversar com Mário Ramos de Oliveira, ele falou que cederia espaço e cederia até a aula, terminando naquela semana mais cedo, por volta das 16 horas, e a faculdade ficou por nossa conta. Todas as salas de aula ficaram por nossa conta a partir das 16 horas o Instituto Oscar Freire e o teatro da faculdade idem! A divulgação também, ela começou um ano antes, na época não tinha e-mail, eram basicamente cartazes, folhetos e boca a boca.

\section{RM: E teve algum outro professor além do Dr. Mário que ajudou no COMU?}

O Mário Ramos na época tinha sido diretor da Faculdade de Medicina do ABC que também tinha um COMU há uns quatro ou cinco anos antes da gente. Ele foi um entusiasta. Na elaboração os outros professores não ajudaram tanto, mas todos eles colaboraram de certa forma. Mas a organização propriamente dita foi feita pelos alunos. O Doutor Mário na verdade foi cedendo o espaço. Por outro lado, nós contamos com apoio de cada um dos professores convidados, em relação a palestras e os cursos.

RM: Quais são as diferenças entre o primeiro congresso que você realizou e o congresso atual que você também participou como presidente de honra?

O congresso, em relação a atividades, agora está maior. Naquela época havia apenas uma semana, diferentemente de hoje em dia que são duas. Nós não tínhamos esse apoio financeiro que existe hoje. Não havia grandes cerimônias, o dinheiro que agente tinha era para cartazes e para os prêmios. Não havia apoio financeiro para coquetel, jantar, lanche, essas coisas. Havia pasta, bloco de anotações, mas bem mais simples do que atualmente. Teve vários stands de laboratórios que haviam feito impressos para o COMU. Nesses stands eram dados vários brindes também.

\section{RM: Qual a importância do COMU e do POC para os acadêmicos?}

A faculdade tem o privilégio de ter alunos muito bons, devido ao forte processo seletivo, portanto os alunos que entram são bem preparados, por outro lado os alunos tem o privilégio de pegar uma estrutura que outras não tem, como o HC, HU outros LIMs. Com o volume e a qualidade que tem aqui certamente não há em nenhum outro lugar do Brasil. Tanto que a USP é a universidade preponderante na área de pesquisa científica e publicação. O COMU, o POC, a RM e o DC assim como as ligas dão vazão a isso. As ligas não existiam nessa forma. O que as ligas fizeram foi oficializar os grupos de estudo que já existiam. Eu trabalhava no grupo no Dr. Noedir Stolf, outros trabalhavam com o Dr. Dario Birolini, outros com o Dr. Pinotti, vários grupos de alunos trabalhando diretamente com o professor, não existia tutor. Hoje o que acontece é que ficou tudo mais profissional. Oficializou-se, com prós e contras, o pró é que fica uma coisa mais transparente, de mais fácil acesso a todos em a seleção é mais clara, o contra é que as pessoas entram com menos convicção porque você tem uma liga e não porque você tem afinidade. Naquela época como não contava crédito não tinha diploma. Só ficava quem queria realmente trabalhar, pois não recebia nada diretamente em troca. Aliás, faltava-se muito em aula para frequientar esses grupos, não tinha período livre, antes não tinha o período para optativas, todo o currículo era nuclear, o que se podia fazer era extracurricular no horário de aula ou, para não faltar, ia-se em horário de almoço, à noite ou final de semana. Faltava-se em muitas aulas para treinar técnica cirúrgica. Mesmo quando se ia à congresso tinha que faltar em algumas aulas.

\section{RM: Hoje em dia esse tipo de prática vale à pena? $\mathrm{O}$ que é melhor liga ou grupo?}

As duas coisas valem à pena. Na prática, elas se misturam. Há muito tempo tem a Liga de Cirurgia Cardiotorácica, a qual eu sou diretor, e a iniciativa foi dos próprios alunos, eles diziam 'olha professor estão surgindo varias ligas na faculdade, porque não fazemos uma também?". E assim surgiu a liga. Para quem gosta de atividades acadêmicas, de investigação cientifica é um belo caminho e cada um se encaixa na área que tem mais afinidade. Eu acho que vale muito à pena, que é um diferencial grande da faculdade, mesmo para quem não vai seguir carreira universitária, acaba abrindo a cabeça e hoje, na verdade, a geração que veio antes 
da minha não tinha residência, depois veio como opcional, como um extensão da graduação e quando eu fiz já era como hoje, obrigatória. O que estou vendo hoje é que a pósgraduação esta virando uma extensão da residência cada vez mais semi-obrigatório, pois hoje em dia os hospitais dão um diferencial para quem tem pós-graduação. Em um passado recente as faculdade não exigiam titulação de pós-graduação aos professores e hoje por exigência do MEC, do CAPES elas estão pedindo, e isso acaba levando as pessoas à fazer pós. Quem teve uma formação durante a faculdade certamente terá mais facilidade de trilhar esse caminho do que quem vai descobrir isso depois da faculdade, por esse motivo acho que vale à pena sim.

\section{RM: O que levou o senhor a fazer cirurgia?}

No final da oitava série o aluno tinha que optar entre humana, exatas ou biológicas. Eu entreguei minha opção em branco, pensei assim: vou ver como funciona a primeira semana do primeiro colegial e depois decidirei que área fazer, no final optei por biológicas. No $2^{\circ}$ colegial eu participava de um laboratório de dessecação de animais no colégio Arquidiocesano. Fiquei muito entusiasmado dissequei animais de todos os filos, chegava a dissecar em casa, decidi então fazer, não só medicina, mas já cirurgia. Entrei na faculdade para fazer cirurgia. Dentre a cirurgia, na época, havia muita reportagem sobre transplante cardíaco e isso me atraia muito. Quando entrei na faculdade uma professora minha do primário me convidou a sua casa para me parabenizar por ter sido aprovado no vestibular. O irmão dela, José Tarik, cirurgião plástico formado aqui na faculdade me perguntou o que eu queria fazer, e falou: - "Venha conversar comigo no meio do ano porque se você quer fazer cirurgia, a melhor coisa é entrar num grupo".

Então ele me apresentou um grupo de amigos da cirurgia cardíaca e quando entrei eu realmente gostei muito, era uma coisa que quanto mais eu fazia, mais eu queria fazer e, a partir daí, passou a ser uma trilha contínua, levando-me a fazer residência e, no final, cirurgia cardíaca.

\section{RM:O que você acha do futuro da cirurgia? Acha que pode acabar?}

"O futuro a Deus pertence". Se você previr, a possibilidade de errar é muito alta. O que existe hoje é uma tendência de não se operar independente de qual seja o procedimento cirúrgico. Por outro lado, na prática, o número de cirurgias tem aumentado principalmente no Brasil onde há uma demanda por cirurgia reprimida. Para se ter uma idéia disso, nos E.U.A. são realizadas 600 mil cirurgias por ano e lá o número de cirurgias tem diminuindo, no Brasil, para uma população que é a metade da norte-americana, fazemos 60 mil cirurgias por ano, mostrando uma demanda reprimida muito grande e um subdiagnóstico muito grande, por outro lado, tudo que você pode tratar com remédio você não vai tratar com cirurgia. Portanto, à medida que o remédio evolui, o número de cirurgias tende a diminuir. Mas também à medida que a engenharia genética evolui, o uso do remédio tende a diminuir. Fazendo, então, uma previsão, você trataria tudo com a genética, morrendo remédio e morrendo cirurgia. Acho que esse dia está muito longe de chegar. Acho que os remédios podem evoluir muito, as cirurgias podem evoluir muito, por exemplo, por vídeo, assim por diante. A cirurgia de trauma não acaba.

\section{RM: O que significou para você ser presidente de honra do XXV COMU?}

Foi muito legal, fiquei muito feliz. Na verdade meio fortuitamente, não conhecia o Leonardo Zorrón, que foi o presidente desse congresso, e através de um boletim informativo da faculdade comecei a me comunicar com ele. Gostei muito, principalmente porque estava a um tempo afastado das atividades do DC. 